\title{
CONSIDERATIONS REGARDING THE QUALITY OF MILITARY TRAINING PROGRAMS
}

\author{
Ştefania BUMBUC \\ “Nicolae Bălcescu” Land Forces Academy, Sibiu, Romania \\ stefanabumbuc@gmail.com
}

\begin{abstract}
In order to provide well-prepared specialists in the military field, the Army ensures the training of its own human resources through initial training programs and then continuous training within the military system and environment. The quality of these training programs, which consume a lot of time and resources, must be evaluated as a process not only as a product, in an authentic and realistic way, according to certain relevant aspects: components of the curricular structure of the training program, quality of adult pedagogy, quality of experiential approaches in teaching and learning, and the difference between the initial and final level of the graduates' competencies. There are a number of issues that can be discussed related to training programs evaluation, and they can be overcome by raising awareness and conceiving the evaluation explicitly for the quality improvement purpose.
\end{abstract}

Keywords: military training, training program, quality evaluation

\section{Introduction}

Increasing the professional knowledge and skills of human resources in all fields is a stringent requirement of the world labour market. Graduates of initial training programs in a profession, and especially graduates of higher education, face a lot of challenges, such as the high dynamics within the professions, the need for interdisciplinarity in solving tasks at the working place, accelerated technological evolution or the desire of employers to be as competitive and relevant as possible in their field of activity. In order to have wellprepared human resources, everyone's attention and efforts must be focused on their education and training programs. More specifically, the quality of educational programs depends on the extent to which graduates respond adequately to the expectations and requirements of employers.

\section{Curricular structure of a military training program}

The Army, as a state institution, is the employer of highly specialized human resources, therefore it also faces the need to have the best prepared personnel in welldefined areas. Through its own education system, through the initial and continuous training programs that it carries out, the army assumes the process of training its own professionals, realizing it almost entirely inside the system and the military environment. This is a very expensive process from many reasons: military personnel have to reach and maintain a high level of competences (so the duration of a training become long), military equipment is becoming more and more performant (and implicitly more expensive) and the military structures need a permanent preparation, in order to be ready any moment at high standards (so the training 
must be repeated periodically).

At the end of any activity that consumes a large amount of resources, it is natural to expect a higher level of results, therefore in military training the results should be commensurate with the investment and consumption of human, material, spiritual and time resources. That is why the quality of military training programs is very important, both in terms of military higher education and in terms of military training in units in the territory, where training in military branches and specialties is carried out.

A training program is a curricular construct that arises from the interaction of four basic components:

- the finalities established to be achieved;

- the contents of the instruction;

- teaching strategies used throughout the program;

- ways to evaluate the outcomes.

The first curricular component, respectively the finalities of the training, is established and validated together with the beneficiaries (namely the future employers of the participants). Thus, the program can have a clear target, in order to guide both the process as a whole and all separate actions taken by trainers and trainees along the way. The second component, respectively the contents, is provided in the NATO documents that ensure the standardization of training. The trainers have to make a pedagogical adaptation and a processing, to bring the content in a form that can be mastered by the military, according to their level and characteristics. The other two components (teaching and evaluation strategies) are mostly developed by the military institution that provides the training program, largely depending on the pedagogical mastery of the trainers. These will be highlighted further.

\section{Adult pedagogy and experiential pedagogy in military training}

Education, training and instruction are three terms used in reference to human resources training activities in the military. Education is the most comprehensive term and refers to the complex and permanent activity, carried out in a conscious and organized way, through which trainers (as individuals and collectively) conduct students, in order to transform them into socially and professionally active personalities, in accordance with the requirements of society and the bio-psychic potential they have [1]. About education, Daniel Buris states that it is "the basic concept that explains why and how things work together and provides the big picture, explaining the art, science, and theory of a phenomenon" [2]. Along with other components, education encompasses both training and instruction as mutually complementary processes. Training, in turn, is considered to be "learner-centered, focused on providing the learners with the information they need to think critically and use judgment in problem solving and complex situations" [3]. As for the instruction, this consists of imparting the skills and procedures required for mastery of a task or competency. It has an external orientation focused on the needs of the profession or vocation. Making a connection between the ideas stated above, we can say that, from a conceptual point of view, the preparation of the military to perform specific professional tasks is done through education, training and instruction, each of them having a different area of coverage, without excluding one on the other.

Participants in military training programs are mostly adults. In literature and in educational practice, a different kind of pedagogy is mentioned when it comes to learners over the age of 25 . The current theory of "andragogy" is proposed by Malcom Knowles [4]. Trainers agree that adults learn differently than children [5], so a training program for adults must follow three basic principles that govern their way of learning: experience, relevance, and reflective thinking [6].

Adults enter a military training program with a rich previous experience, which 
influences them very strongly and which complements what the training program offers [7]. The theoretical model explicitly followed by many educational institutions that address adult learners is "The Experiential Learning Model” elaborated by Kolb [8]. According to this conceptual framework, in the training of adults it starts from their pre-existing experiences and from the concrete tasks to be solved, then the trainers offer a new and useful content (information, procedures, etc.), to finally challenge participants to analyze and reflect on what they have learned valuable for the future.

Regarding the relevance of the proposed content for learning, it should be borne in mind that the military do not necessarily have intellectual concerns, do not necessarily seek to accumulate as much knowledge as possible, but instead they are all very interested in those content that is useful to efficiently accomplish professional tasks. Both the retention of information and the improvement of skills are closely related to the relevance of them in the context of the personal and professional life of the military.

If we refer to the third requirement to be met in adult education, namely the critical approach to content, we mention that "reflective thinking requires the continual evaluation of beliefs, assumptions, and hypotheses against existing information and against other plausible interpretations" [9]. Given that self-direction is a very important feature of adult learning, it is a matter of the trainers' talent not to treat military as inexperienced children who need guidance and tutoring, but also not to consider that they are completely autonomous learners and can manage on their own, getting only a few indications [10]. A balanced combination of adult autonomy and teacher guidance and resourcing is needed.

\section{Evaluating the quality of a military training program}

The education of the military is led by trainers from within the military system, in a professional manner. These are military and civilian teachers, officers and military instructors who are tasked with delivering relevant and effective programs tailored to the requirements of military missions. "Army educational institutions and schools cannot stay static, as their educational product changes with the Army mission set and the operational environment” [11].

Although the issue of the quality of military training programs is a great concern to all unit commanders and decision makers in the field, a surprising fact is reported by Salas, Milham and Bowers.: "Due to a number of misconceptions about training evaluation in the military, these evaluations are rarely done." [12]. The abovementioned authors consider that once a training program has been created, the logistics and the solutions to carry out the individual and collective training of the military have been established, the temptation is to continue the process for a long time, with the conviction that the training is efficient and without actually perform objective evaluation or accurately measuring the results. There is, of course, an assessment of the military acquisitions at the end of a training program, aiming to identify the extent to which they have reached the level of competence proposed as a target. But the quality of the training program is not really assessed, to determine whether the same results could not be achieved in a shorter time, consuming fewer resources, using more efficient methods or whether the results could not be better, under the given conditions. In this context, a number of questions are absolutely relevant, related to the quality of training, to the extent that the expensive simulators and military equipment really have the desired effects in training the skills needed by fighters or whether participants in a training program actually have learned what they need in the missions that will be assigned to them.

Specialists noted the precariousness of clear tools and procedures for assessing the 
quality of training programs, as well as a number of biases of the military related to this issue, such as:

- the effectiveness of a training program cannot be really evaluated because a group of untrained soldiers (as a control group) cannot be sent on a mission to later compare the results with the experimental group;

- whereas the purpose of the military training is "to be ready", to always be prepared for an intervention in an unpredictable situation, the requirements of which cannot be anticipated and clearly described, it is difficult to determine the level reached by each military in this regard, to adapt the course of the instruction accordingly;

- there is no need to evaluate in artificial conditions something that is obviously going well, because only on the battlefield it will be possible to really see the quality and efficiency of the trainig;

- the quality of training depends on the use of simulators and other military equipment, and as long as they work and are used by the military, it means that the training program is good.

All these refractory ideas and attitudes can be overcome depending on the methods used in evaluation. For example, the quality of a training program can be assessed by observing the differences between the initial and final level of participants' acquisitions, measuring several key indicators (behaviors), some of which are practiced during the program and some are not. This avoids the possible error of misunderstanding the results of the training, considering the fact that the progress of some people in certain aspects does not necessarily appear as a result of the training program in which they participated. By measuring relevant behaviors of participants can be also compared the quality of different instructional programs.

Along with the ways of performing the evaluation (how is done), it is equally important what is evaluated, respectively what is tested, measured, observed, recorded. Among these aspects we can highlight the following:

- the degree of the participants' satisfaction at the end of the training program;

- learning outcomes (closely related to what the trainers explicitly and intentionally taught during the program);

- cognitive outcomes (factual and procedural knowledge held by participants);

- behavioral outcomes (how participants perform a task in the context of the training program);

- results at the organizational level (the extent to which graduates of a training program generate changes in the organizations they belong to and the extent to which they contribute to the achievement of the organizations' goals). All these types of results also indicate with what intensity and after what time the training of the military must be repeated after completing a training program, given the fact that the military must always be prepared.

An important idea is that things are evolving in the military profession, as in the case of other professions, in the direction of moving the center of gravity from the physical component to the intellectual ones, related to the way people think and make decisions. This change is due to the largely use of advanced military technology, which accomplish much of the tasks traditionally held by the military. Therefore, in order to be relevant, the evaluation of the quality of a training program should take more and more into account indicators with cognitive reference.

\section{Conclusions}

Any military training program can be improved, no matter how successful it may seem, only if the assessments are explicitly intended to improve things, not just to make a diagnosis.

As we have detailed, the value of a training 
program means more than easily observable and quantifiable aspects, such as training facilities, materials and technical equipment, correctness and timeliness of the contents from manuals and official documents of the military institution. Not even the level of graduates' competence at the final evaluations is an entirely relevant indicator for the quality of the training program. This is because a competence in the military field can be demonstrated only in a real professional context, in the permanent dynamics of military missions. Therefore, in order to increase the level of professional competences of the military, good quality training programs are needed, and this can be ensured subsequently to an authentic, complex, multicriteria and multidimensional evaluation process, in which human resources have an essential role.

\section{References List}

[1] Nicola I. Tratat de pedagogie şcolară. Bucureşti: Editura Aramis; 2000.

[2] Burris D. Teach a Man to Fish: Training vs. Education. HuffPost. 10.06.2015. Available from: http://www.huffingtonpost.com/daniel-burrus/teach-aman-to-fish-training-vseducation_b_7553264.html

[3] Pierson D. Reengineering Army Education for Adult Learners. Journal of Military Learning. October 2017: 31-43.

[4] Knowles M. Andragogy in Action: Applying Modern Principles of Adult Learning. San Francisco: Jossey-Bass; 1984.

[5] Cercone K. Characteristics of Adult Learners with Implications for Online Learning Design. AACE Journal. 2008; 16 (2):137-159.

[6] U.S. Army Training and Doctrine Command. Army Educational Process, TRADOC Pamphlet 350-70-7, January 2018, p.13.

[7] Ibidem, p.16.

[8] Kolb D.A. Experiential Learning: Experience as the Source of Learning and Development. Pearson Education Inc; 1984.

[9] King P., Kitchener K. Developing Reflective Judgment: Understanding and Promoting Intellectual Growth and Critical Thinking in Adolescents and Adults. San Francisco: Jossey-Bass Publishers; 1994.

[10] Edmondson D., Boyer S., Artis A. Self-directed Learning: A Meta-analytic Review of Adult Learning Constructs. International Journal of Education Research. 2012; 7: 40-48.

[11] U.S. Army Training and Doctrine Command. Army Educational Process, TRADOC Pamphlet 350-70-7, January 2018, p.8.

[12] Salas E., Milham L.M., Bowers C.A. Training Evaluation in the Military: Misconceptions, Opportunities, and Challenges. Military Psychology. 2003; 15(1): 3-16. 